\title{
Article
}

\section{Pediatric Chronic Migraine Severity and Maternal Stress}

\author{
Daniela Smirni $^{1, *(1)}$ and Marco Carotenuto ${ }^{2}$ (D) \\ 1 Department of Psychology, Educational Science and Human Movement, University of Palermo, \\ 90128 Palermo, Italy \\ 2 Clinic of Child and Adolescent Neuropsychiatry, Department of Mental Health, Physical and Preventive \\ Medicine, Università degli Studi della Campania “Luigi Vanvitelli”, 81100 Caserta, Italy; \\ marco.carotenuto@unicampania.it \\ * Correspondence: daniela.smirni@unipa.it; Tel.: +39-09123897748
}

\section{check for}

updates

Citation: Smirni, D.; Carotenuto, M. Pediatric Chronic Migraine Severity and Maternal Stress. Pediatr. Rep. 2021, 13, 576-582. https://doi.org/ $10.3390 /$ pediatric 13040068

Academic Editor: Giovanni Biondi

Received: 4 September 2021

Accepted: 12 October 2021

Published: 15 October 2021

Publisher's Note: MDPI stays neutral with regard to jurisdictional claims in published maps and institutional affiliations.

Copyright: (c) 2021 by the authors. Licensee MDPI, Basel, Switzerland. This article is an open access article distributed under the terms and conditions of the Creative Commons Attribution (CC BY) license (https:/ / creativecommons.org/licenses/by/ $4.0 /)$.

\begin{abstract}
Primary headache is an increasing phenomenon in pediatric age, and very often, it causes disabling limitations in children's daily activities, negatively affecting family well-being. There are conflicting data in the literature on the impact of children's migraines on parental experienced stress. This study aimed to evaluate maternal stress in a sample of school-aged children with a migraine without aura (MwoA) and its correlation with migraine intensity and frequency. A total of 474 mothers aged between 31 and 55 participated in the study: 237 were mothers of children with MwoA, and 237 were mothers of typical developing children. All participants were administered the Parent Stress Index-Short Form (PSI-SF) for the assessment of parental stress; the Pediatric Migraine Disability Assessment (PedMIDAS) was administered to children with MwoA to assess the presence of a related disability migraine. The results showed a significantly higher rate of stress in mothers of MwoA children $(p<0.001)$ in all the domains explored by the PSI-SF and a statistically significant correlation between the maternal stress total score and the intensity and frequency of migraine attacks $(p<0.0001)$. This study highlights the need for the holistic contribution of the family to be considered in the clinical management of pediatric migraines.
\end{abstract}

Keywords: primary headache; maternal stress; migraine without aura; PedMIDAS

\section{Introduction}

A migraine is the most common cephalic pain in the developmental age [1], with the overall prevalence estimated to be about 9.1\% (95\% CI: 7.1-11.1) [2]. Chronic migraine is a disabling neurological disease with its relevant impact on quality of life negatively related to pain severity [3]. In fact, a recurring headache and the need for frequent medical examinations tend to negatively affect family well-being, and actually, up to $18 \%$ of admissions to the pediatric emergency department are due to primary headaches [4].

Moreover, in the developmental age, chronic migraine seems to often be associated with psychiatric, neurological and cardiac comorbidities [5]; learning impairment [6] and sleep problems [7-10].

To date, few studies have explored the impact of headache on parental stress with debating and conflicting results. Esposito et al. found that parents of children with a migraine without aura have higher stress levels than parents of healthy children [11]. On the contrary, Barone et al. and Operto et al. found no difference in the parenting stress of children with or without primary headaches [12,13].

An increasing number of studies have recently investigated how emotional/behavioral problems in children are associated with chronic disorders such as migraines; however, knowledge of the relationship between these problems and parental stress is still limited [14-17]. In general, parents of children with chronic medical, neurological or psychiatric conditions show elevations of perceived stress levels and a reduction of parental quality [18-22], and specifically, children with headaches seem to be at a high risk for psy- 
chological maladjustment, including internalizing disorders [23,24]. Within this perspective, the literature has reported how managing a problematic child can become a significant source of stress for parents, especially for the mother as the primary caregiver [21,25].

It is important to consider that parental stress can affect the child's emotional disturbances, and this, in turn, can negatively affect the child's pain perception [26]. Therefore, investigating the relationship between migraine in the child and primary caregiver stress is crucial for the proper management of this condition.

However, some studies have also documented that a sympathetic progression and involvement of the autonomic system and the hypothalamus-pituitary-adrenal (HPA) axis could be at the basis of the neurobiological mechanism that favors migraine attacks and favors the development of chronic migraines, amplifying maternal stress [27-29]. Moreover, we cannot also exclude the role of the orexin/serotoninergic pathway interaction, the consequent dysregulation of wake-sleep cycling and the pain perception in migraine subjects independently from age [30] and the mutual effect of parenting stress and pediatric sleep troubles in MwoA children [31].

Although pediatric primary headaches are today a hot research topic, only a few studies have focused on the correlation between migraine severity and the degree of parental stress, and their results have often been contrasting. Therefore, this study aimed to evaluate maternal stress in a sample of school-aged children with migraine without aura (MwoA) and its putative correlation with migraine intensity, frequency and disability severity.

\section{Materials and Methods}

\subsection{Participants}

A sample of 474 mothers aged between 31 and 55 years (mean age $44.5 \pm 8.15$ years) participated in the study. The participants were all Caucasians, native Italian speakers and from a common mid-level socioeconomic status. The mothers participating in the study were all married women with stable and non-separated relationships.

The study sample was divided into two groups. The first group consisted of 237 mothers of children with MwoA (120 boys and 117 girls; mean age $8.01 \pm 1.45$ years), recruited as inpatients from 2003 until 2013 at the Clinic for Child and Adolescent Neuropsychiatry of the University of Campania "Luigi Vanvitelli". The diagnosis of MwoA had been made by a trained and expert-in-the-field physician (M.C.), and it was revaluated according to the third edition of the International Classification of Headache Disorders (ICHD-3) [32].

The second group consisted of 237 mothers of typically developing children (TDC) without migraine (122 males and 115 females; mean age $7.94 \pm 1.63$ years) from the same geographic region as the mothers in the first group. The mothers of the TDC children were randomly recruited from the parents of children attending public schools in Campania as part of a study on the typical neurological development of school-age and adolescent children.

Inclusion criteria for eligibility in the study were to be mothers of children that were:

(1) Males and females aged 6 to 12 years (inclusive);

(2) Of a typical neurodevelopment or with a diagnosis of migraine without aura, as e-evaluated by the HIS ICHD-3 guidelines (1.1 or 1.2 according to ICHD-3).

For the latter, in addition, they had:

- a history of migraine without aura of at least 6 months;

- a history of 4-14 migraine headache days and with at least 4 migraine attacks per month;

- a Pediatric Migraine Disability Assessment Scale (PedMIDAS) score $>20$ and $<140$ at first visit.

Mothers were excluded from recruitment if their children had:

(1) a psychiatric disorder, as reviewed by the Diagnostic and Statistical Manual of Mental Disorders, 5th edition [33] (i.e., psychosis, bipolar disorder, major depression, generalized anxiety disorder, post-traumatic stress disorder);

(2) documented neurodevelopmental disorders (i.e., autism spectrum disorders, cerebral palsy or cognitive impairment, ADHD); 
(3) active and/or significant risk of suicide;

(4) an acute, severe or unstable medical condition.

\subsection{Parenting Stress Index-Short Form (PSI-SF)}

To assess parental stress, the Italian version of the PSI-SF was administered to all participants [11,13,25,34,35].

The PSI-SF is a standardized self-administration questionnaire that provides scores on three different scales: (1) Parental Distress; (2) parent-child interaction; (3) difficult child.

The Parental Distress subscale evaluates the parent's stress, per se. The parent-child interaction subscale evaluates the stress caused by the parent-child interaction. The difficult child subscale measures the stress of managing a child who appears more problematic than the parent expected.

The PSI-SF has 36 elements, based on a five-point Likert scale $(1=$ completely disagree; $5=$ completely agree). The subscale scores range from 12 to 60 , and the Total Stress score ranges from 36 to 180 . The higher the score is, the greater the parental stress level $[11,13,25,34,35]$.

The PSI-SF showed high internal consistency (Cronbach's alpha: 0.92), and its reliability and validity have been widely reported, even in parents of children with chronic conditions. In the present study, the three subscales had adequate internal reliability (Cronbach's alpha ranging from 0.57 to 0.70 ) $[11,13,25,34,35]$.

\subsection{Pediatric Migraine Disability Assessment (PedMIDAS)}

The Pediatric Migraine Disability Assessment (PedMIDAS) was completed by the child, the mother or both together. It is the only validated tool for assessing migraine disability among school-aged children. This tool consists of six questions that investigate the impact of migraines on daily activities and overall quality of life. The PedMIDAS has been validated and proven reliable for assessing migraine-related disability in children and adolescents. It is also useful for evaluating the results of interventions and comparing responses to different treatments [36].

\section{Ethical Approval}

The present study was conducted according to the principles of the Declaration of Helsinki [37]. The Ethics Committee at the Università degli Studi della Campania "Luigi Vanvitelli" approved the retrospective study design and all procedures, considering the adherence with international guidelines (Protocol code 0022404/i; 23 July 2021). Informed consent was obtained from all subjects involved in the study.

\section{Statistical Analysis}

The two groups were compared for demographic characteristics using an independent $t$-test. The independent $t$-test was also performed to compare the PSI-SF performance of the mothers of the two groups (MwoA vs. TDC). In addition, correlational analyses were carried out to verify if there was a relationship between the frequency, intensity and duration of migraine episodes and the level of parental stress. For all analyses, $p$ values $\leq 0.05$ were considered as statistically significant. The software Statistica version 8.1 (StatSoft Inc., Tulsa, OK, USA) was used for all statistical tests.

\section{Results}

No differences in age $(t$-test $(472)=0.53 ; p=0.59)$ nor in education $(t$-test $(472)=1.52$; $p=0.13$ ) were found between the two groups.

As expected, comparing the stress levels of mothers of children with migraine problems and mothers of TDC, the mean comparisons of all parameters measured by the stress scale were statistically significant and had a very large effect size (Table 1). According to Sawilowsky's "New Effect Size Rules of Thumb", a Cohen's d over 2 indicates a huge effect size [38]. 
Table 1. Mean comparison in the Parent Stress Index-Short Form (PSI-SF) between parents of children with migraine problems and typical developing children parents (TDC).

\begin{tabular}{cccccccc}
\hline \multirow{2}{*}{ PSI-SF Scale } & \multicolumn{2}{c}{ Migraine } & \multicolumn{2}{c}{ TDC } & $\mathbf{t}$ & \multirow{2}{*}{$\boldsymbol{p}$} & \multirow{2}{*}{ Cohen's d } \\
\cline { 2 - 6 } & $\mathbf{M}$ & $\mathbf{S D}$ & $\mathbf{M}$ & $\mathbf{S D}$ & $\mathbf{( d f}=\mathbf{4 7 2})$ & & \\
\hline Parental distress & 28.02 & 5.82 & 16.02 & 2.23 & 29.63 & $<0.0001$ & 2.72 \\
Parent-child & 32.44 & 5.20 & 15.67 & 2.37 & 45.18 & $<0.0001$ & 4.15 \\
interaction & & & & & & & \\
Difficult child & 31.23 & 5.62 & 16.77 & 1.67 & 37.99 & $<0.0001$ & 3.49 \\
Stress total score & 91.69 & 11.75 & 48.47 & 5.24 & 51.69 & $<0.0001$ & 4.75 \\
\hline
\end{tabular}

PSI-SF: Parent Stress Index-Short Form; t: $t$-test; $p: p$-value; df: degrees of freedom; M: mean; SD: standard deviation.

Furthermore, the correlational analyses revealed positive and significant correlations between maternal stress levels and the intensity $(\mathrm{r}=0.40 ; p<0.0001)$ and frequency $(\mathrm{r}=0.54$, $p<0.0001)$, but not duration ( $\mathrm{r}=0.07 ; p=0.253)$, of MwoA attacks (Table 2).

Table 2. Correlation between frequency, duration, intensity and degree of headache-associated disability and parent's total stress score.

\begin{tabular}{ccc}
\hline & \multicolumn{3}{c}{ Total Stress Score } \\
\cline { 2 - 3 } & $\mathbf{r}$ & $p$ \\
\hline Frequency & 0.54 & $<0.0001$ \\
Duration & 0.07 & 0.253 \\
Intensity & 0.40 & $<0.0001$ \\
PedMIDAS & 0.62 & $<0.0001$ \\
\hline
\end{tabular}

r: correlation's coefficient; $p$ : $p$-value; PedMIDAS: Pediatric Migraine Disability Assessment.

\section{Discussion}

The findings of the present study highlighted a suggestive relationship between the subjectively perceived maternal stress levels and the MwoA frequency, intensity and disability.

The clinical management of migraines in the developmental age is complex and also involves also the whole family. In 2013, Esposito et al. reported PSI-SF data from 218 children with MwoA and compared them to a large group of typically developing children, showing that parents of children with MwoA had significantly higher Parental Distress scores on the Parent-Child Interaction subscale, in the Difficult Child subscale and in Total Stress Score [11].

On the contrary, in 2015, Barone et al. compared the parental stress of 71 school-aged children with a headache (mean age $9.8 \pm 1.3$ years) and 71 typical developing children (mean age $9.2 \pm 1$ years), highlighting no difference between groups for parenting stress, using the PSI-SF to investigate stress perceived [12].

Similarly, in 2018, Operto et al., assessing 35 adolescents (mean age $14.89 \pm 3.2$ years) with migraine and 23 healthy adolescents (mean age $14.75 \pm 3.17$ years) through the PSI$\mathrm{SF}$, found no difference in terms of parenting stress $(p=0.29)$. However, interestingly, they found more internalizing problems $(p=0.023)$, affective problems $(p<0.01)$, anxious $(p<0.001)$, and somatic complaints $(p<0.001)$ among the headache group compared to control group [13].

On the other hand, the cited reports assessed only the perceived parental stress levels among the mothers of children affected by MwoA, without evaluating the possible correlation with the attacks intensity and frequency and not even with the disability degree. In fact, these are relevant parameters in clinical practice to calibrate the degree of severity of the individual patient and the effectiveness of the therapy.

The results of the present study showed a significantly higher rate of stress in mothers of children with MwoA $(p<0.0001)$, with a huge size effect in all the domains explored by the PSI-SF. Particularly, the chronical pain condition may contribute to create a false image of one's child who only appears sick, and therefore, it is difficult to interact with 
him or her. Above all, it must be considered that any chronic pathology in pediatric age tends to alter the parental quality itself, with feelings of inadequacy and guilt on the part of the parents [20]. In this light, we can explain the perception of one's child as difficult (Difficult child domain; $p<0.0001$ ) as suffering from a chronic and disabling disease, such as MwoA at high frequency. However, it should be emphasized that this sort of rejection is due to the child's pathology, a situation that generates feelings of helplessness in the parent (Parent-Child Interaction domain, $p<0.0001$ ).

Moreover, this data can be considered as a relevant suggestion about the importance of coping strategies in chronic diseases, considering the significant negative impact on children's daily lives and their families $[39,40]$. This may explain the higher values in the Parent-child interaction and Difficult child subscales among mothers of children with MwoA $(p<0.0001)$.

Furthermore, the novelty of the present study can be identified in the correlational analyses between maternal stress levels and the frequency, intensity and duration of MwoA attacks. These analyses revealed that the degree of headache-associated disability (PedMIDAS) was strongly linked to the parent's total stress level. On the other hand, the duration of migraine episodes was not related to the parent's stress level.

It is conceivable that maternal stress, in turn, can increase the stress of the child, affecting the severity of the migraine. It is now widely recognized that chronic stress also is related to headache in developmental age [41,42], and in general, migraine attacks can be explained as a genetically determined adaptive behavioral response to stressors, internal or external, of a brain that feels threatened [43].

The neurobiological mechanisms by which stress could trigger migraine attacks and promote the development of a chronic migraine are unclear, although the dysfunction of the autonomic system and the hypothalamic-pituitary-adrenal (HPA) axis may be involved. Supportive of the presence of sympathetic dysfunction, serotonin and norepinephrine levels have been demonstrated to be lower in both those with PTSD and those with migraines $[27,30,44]$.

Neurophysiological studies have shown abnormal cortical excitability and information processing in patients with migraines. It is possible that stress can produce neurochemical changes in the cerebral cortex, promoting migraine attacks [28].

In this scenario, Silvestro et al. showed that the imbalance between the need of investing resources to promote cerebral network efficiency and the need of minimizing the metabolic cost of wiring probably represents the mechanism underlying migraine patients' susceptibility to triggers [45].

In general, we can consider the correlation between frequency, intensity and disability degree and maternal perceived stress as relevant. In fact, each chronic disease impacts the quality of life of the family and children affected, causing a stressful condition in pediatric age, with psychological troubles also in intra-familiar relationships [46]. Moreover, we can also speculate that frequent specialist clinical visits, the consequent perception of the sickness status and the effect of denial and rejection by parents of their child's pathology may be the reasons underlying the high maternal stress related to the clinical characteristics of MwoA.

Therefore, children with MwoA may be more likely to benefit from behavioral interventions to improve stress assessment and coping strategies for treatment.

The current study's main limitation is the lack of information on the stress level of fathers. As in a previous study on stress in parents of children with enuretic problems, it would be interesting to observe any differences in stress levels between mothers and fathers [21]. The choice to analyze only mothers' stress levels arose from literature data which reported that mothers are more vulnerable to stress than fathers.

Author Contributions: Conceptualization, M.C.; methodology, D.S. and M.C.; formal analysis, M.C.; data curation, M.C. and D.S.; writing-original draft preparation, M.C.; writing-review and editing, M.C. and D.S. All authors have read and agreed to the published version of the manuscript. 
Funding: This research received no external funding.

Institutional Review Board Statement: The study was conducted according to the guidelines of the Declaration of Helsinki, and it was approved by the Ethics Committee of the Università degli Studi della Campania "Luigi Vanvitelli" (Protocol code 0022404/I; 23 July 2021).

Informed Consent Statement: Informed consent was obtained from all subjects involved in the study.

Data Availability Statement: Data supporting the reported results can be obtained on request.

Conflicts of Interest: The authors declare no conflict of interest.

\section{References}

1. Abu-Arefeh, I.; Russell, G. Prevalence of headache and migraine in schoolchildren. BMJ 1994, 309, 765-769. [CrossRef] [PubMed]

2. Wöber-Bingöl, Ç. Epidemiology of migraine and headache in children and adolescents. Curr. Pain Headache Rep. 2013, 17, 1-11. [CrossRef] [PubMed]

3. Leonardi, M.; Grazzi, L.; D’Amico, D.; Martelletti, P.; Guastafierro, E.; Toppo, C.; Raggi, A. Global Burden of Headache Disorders in Children and Adolescents 2007-2017. Int. J. Environ. Res. Public Health 2021, 18, 250. [CrossRef] [PubMed]

4. Vetri, L.; Messina, L.M.; Drago, F.; D’Aiuto, F.; Vanadia, F.; Brighina, F.; Raieli, V. Are paediatric headaches in the emergency department increasing? An Italian experience. Funct. Neurol. 2019, 34, 188-195.

5. Bellini, B.; Arruda, M.; Cescut, A.; Saulle, C.; Persico, A.; Carotenuto, M.; Gatta, M.; Nacinovich, R.; Piazza, F.P.; Termine, C. Headache and comorbidity in children and adolescents. J. Headache Pain 2013, 14, 79. [CrossRef]

6. Onofri, A.; Olivieri, L.; Silva, P.; Bernassola, M.; Tozzi, E. Correlation between primary headaches and learning disabilities in children and adolescents. Minerva Pediatr. 2021. [CrossRef]

7. Carotenuto, M.; Guidetti, V.; Ruju, F.; Galli, F.; Tagliente, F.R.; Pascotto, A. Headache disorders as risk factors for sleep disturbances in school aged children. J. Headache Pain 2005, 6, 268. [CrossRef]

8. Roccella, M.; Marotta, R.; Operto, F.; Smirni, D.; Precenzano, F.; Bitetti, I.; Messina, G.; Sessa, F.; Di Mizio, G.; Loreto, C.; et al. NREM sleep instability in pediatric migraine without aura. Front. Neurol. 2019. [CrossRef]

9. Vendrame, M.; Kaleyias, J.; Valencia, I.; Legido, A.; Kothare, S.V. Polysomnographic findings in children with headaches. Pediatr. Neurol. 2008, 39, 6-11. [CrossRef]

10. Esposito, M.; Roccella, M.; Parisi, L.; Gallai, B.; Carotenuto, M. Hypersomnia in children affected by migraine without aura: A questionnaire-based case-control study. Neuropsychiatr. Dis. Treat. 2013, 9, 289. [CrossRef]

11. Esposito, M.; Gallai, B.; Parisi, L.; Roccella, M.; Marotta, R.; Lavano, S.M.; Gritti, A.; Mazzotta, G.; Carotenuto, M. Maternal stress and childhood migraine: A new perspective on management. Neuropsychiatr. Dis. Treat. 2013, 9, 351-355. [CrossRef]

12. Barone, L.; Lionetti, F.; Dellagiulia, A.; Galli, F.; Molteni, S.; Balottin, U. Behavioural problems in children with headache and maternal stress: Is children's attachment security a protective factor? Infant Child Dev. 2016, 25, 502-515. [CrossRef]

13. Operto, F.F.; Craig, F.; Peschechera, A.; Mazza, R.; Lecce, P.A.; Margari, L. Parenting stress and emotional/Behavioral Problems in adolescents with Primary headache. Front. Neurol. 2018, 8, 749. [CrossRef] [PubMed]

14. Pinquart, M.; Shen, Y. Behavior problems in children and adolescents with chronic physical illness: A meta-analysis. J. Pediatr. Psychol. 2011, 36, 1003-1016. [CrossRef]

15. Thabrew, H.; McDowell, H.; Given, K.; Murrell, K. Systematic review of screening instruments for psychosocial problems in children and adolescents with long-term physical conditions. Glob. Pediatr. Health 2017, 4. [CrossRef] [PubMed]

16. Stawski, M.; Auerbach, J.G.; Barasch, M.; Lerner, Y.; Zimin, R.; Miller, M.S. Behavioral problems of adolescents with chronic physical illness: A comparison of parent-report and self-report measures. Eur. Child Adolesc. Psychiatry 1995, 4, 14-20. [CrossRef]

17. Operto, F.F.; Smirni, D.; Scuoppo, C.; Padovano, C.; Vivenzio, V.; Quatrosi, G.; Carotenuto, M.; Precenzano, F.; Maria, G.; Pastorino, G. Neuropsychological Profile, Emotional/Behavioral Problems, and Parental Stress in Children with Neurodevelopmental Disorders. Brain Sci. 2021, 11, e584. [CrossRef]

18. Hasson-Ohayon, I.; Tuval-Mashiach, R.; Morag-Yaffe, M.; Gaziel, M.; Schapir, L.; Zalsman, G.; Shoval, G. Parents of adolescents with psychiatric disorders: Insight into the disorder, self-stigma and parental stress. Compr. Psychiatry 2014, 55, 1106-1110. [CrossRef]

19. Graj, E.; Muscara, F.; Anderson, V.; Hearps, S.; McCarthy, M. Quality of life in parents of seriously Ill/injured children: A prospective longitudinal study. Qual. Life Res. 2021, 30, 193-202. [CrossRef]

20. Marotta, R.; Precenzano, F.; Operto, F.F.; Lanzara, V.; Risoleo, M.C.; Vetri, L.; Parisi, L.; Pastorino, G.M.G.; Gallai, B.; Scarinci, A. Nocturnal obstructive respiratory events severity is associated with low parental quality. Curr. Pediatr. Res. 2020, $24,194-198$.

21. Roccella, M.; Smirni, D.; Smirni, P.; Precenzano, F.; Operto, F.F.; Lanzara, V.; Quatrosi, G.; Carotenuto, M. Parental Stress and Parental Ratings of Behavioral Problems of Enuretic Children. Front. Neurol. 2019, 10. [CrossRef]

22. Precenzano, F.; Smirni, D.; Vetri, L.; Marzuillo, P.; Lanzara, V.; Bitetti, I.; Siciliano, M.; Miraglia del Giudice, E.; Esposito, M.; Santoro, N.; et al. Childhood Obesity and Maternal Personality Traits: A New Point of View on Obesity Behavioural Aspects. Pediatr. Rep. 2021, 13, 538-545. [CrossRef]

23. Pakalnis, A.; Butz, C.; Splaingard, D.; Kring, D.; Fong, J. Emotional problems and prevalence of medication overuse in pediatric chronic daily headache. J. Child Neurol. 2007, 22, 1356-1359. [CrossRef] 
24. Puca, F.; Genco, S.; Prudenzano, M.P.; Savarese, M.; Bussone, G.; D’Amico, D.; Cerbo, R.; Gala, C.; Coppola, M.T.; Gallai, V. Psychiatric comorbidity and psychosocial stress in patients with tension-type headache from headache centers in Italy. Cephalalgia 1999, 19, 159-164. [CrossRef]

25. Smirni, D.; Carotenuto, M.; Precenzano, F.; Smirni, P.; Operto, F.F.; Marotta, R.; Roccella, M. Memory performances and personality traits in mothers of children with obstructive sleep apnea syndrome. Psychol. Res. Behav. Manag. 2019, 12, 481-487. [CrossRef] [PubMed]

26. Neece, C.L.; Green, S.A.; Baker, B.L. Parenting stress and child behavior problems: A transactional relationship across time. Am. J. Intellect. Dev. Disabil. 2012, 117, 48-66. [CrossRef] [PubMed]

27. Peterlin, B.L.; Nijjar, S.S.; Tietjen, G.E. Post-traumatic stress disorder and migraine: Epidemiology, sex differences, and potential mechanisms. Headache J. Head Face Pain 2011, 51, 860-868. [CrossRef] [PubMed]

28. Sauro, K.M.; Becker, W.J. The stress and migraine interaction. Headache J. Head Face Pain 2009, 49, 1378-1386. [CrossRef] [PubMed]

29. Smirni, D. Noli Timere: The Role of Reassuring Adults in Dealing with COVID-19 Anxiety in Pediatric Age. Pediatr. Rep. 2021, 13, 15-30. [CrossRef]

30. Messina, A.; Bitetti, I.; Precenzano, F.; Iacono, D.; Messina, G.; Roccella, M.; Parisi, L.; Salerno, M.; Valenzano, A.; Maltese, A.; et al. Non-Rapid Eye Movement Sleep Parasomnias and Migraine: A Role of Orexinergic Projections. Front. Neurol. 2018, 9 , 95. [CrossRef]

31. Byars, K.C.; Yeomans-Maldonado, G.; Noll, J.G. Parental functioning and pediatric sleep disturbance: An examination of factors associated with parenting stress in children clinically referred for evaluation of insomnia. Sleep Med. 2011, 12, 898-905. [CrossRef]

32. Arnold, M. Headache classification committee of the international headache society (IHS) the international classification of headache disorders. Cephalalgia 2018, 38, 1-211.

33. American Psychiatric Association. Diagnostic and Statistical Manual of Mental Disorders, 5th ed.; American Psychiatric Association: Washington, DC, USA, 2013.

34. Abidin, R.R. Parenting Stress Index —Short Form Manual; Western Psychological Services: Los Angeles, CA, USA, 1990.

35. Abidin, R.R. Parenting Stress Index Third Edition: Professional Manual; Psychological Assessment Resources: Lutz, FL, USA, 1995.

36. Hershey, A.D.; Powers, S.W.; Vockell, A.-L.; LeCates, S.; Kabbouche, M.A.; Maynard, M.K. PedMIDAS: Development of a questionnaire to assess disability of migraines in children. Neurology 2001, 57, 2034-2039. [CrossRef]

37. Association, W.M. World Medical Association Declaration of Helsinki: Ethical principles for medical research involving human subjects. JAMA 2013, 310, 2191-2194. [CrossRef]

38. Sawilowsky, S.S. New effect size rules of thumb. J. Mod. Appl. Stat. Methods 2009, 8, 26. [CrossRef]

39. Langeveld, J.H.; Koot, H.M.; Passchier, J. Headache intensity and quality of life in adolescents. How are changes in headache intensity in adolescents related to changes in experienced quality of life? Headache J. Head Face Pain 1997, 37, 37-42. [CrossRef] [PubMed]

40. Frare, M.; Axia, G.; Battistella, P.A. Quality of life, coping strategies, and family routines in children with headache. Headache J. Head Face Pain 2002, 42, 953-962. [CrossRef]

41. Passchier, J.; Orlebeke, J.F. Headaches and stress in schoolchildren: An epidemiological study. Cephalalgia 1985, 5, 167-176. [CrossRef] [PubMed]

42. Carlsson, J.; Larsson, B.; Mark, A. Psychosocial functioning in schoolchildren with recurrent headaches. Headache J. Head Face Pain 1996, 36, 77-82. [CrossRef]

43. Cortelli, P.; Pierangeli, G.; Montagna, P. Is migraine a disease? Neurol. Sci. 2010, 31, 29-31. [CrossRef]

44. Tietjen, G.E.; Peterlin, B.L. Childhood abuse and migraine: Epidemiology, sex differences, and potential mechanisms. Headache J. Head Face Pain 2011, 51, 869-879. [CrossRef] [PubMed]

45. Silvestro, M.; Tessitore, A.; Caiazzo, G.; Scotto di Clemente, F.; Trojsi, F.; Cirillo, M.; Esposito, F.; Tedeschi, G.; Russo, A. Disconnectome of the migraine brain: A “connectopathy" model. J. Headache Pain 2021, 22, 1-11. [CrossRef] [PubMed]

46. Carotenuto, M.; Esposito, M.; Di Pasquale, F.; De Stefano, S.; Santamaria, F. Psychological, cognitive and maternal stress assessment in children with primary ciliary dyskinesia. World J. Pediatr. 2013, 9, 312-317. [CrossRef] [PubMed] 